\title{
Intradialytic hyperalimentation as adjuvant support in pregnant hemodialysis patients: case report and review of the literature
}

\author{
Delphine Tuot $\cdot$ Suzanne Gibson $\cdot$ Aaron B. Caughey \\ Lynda A. Frassetto
}

Received: 23 March 2009/Accepted: 21 October 2009/Published online: 13 November 2009

(C) The Author(s) 2009. This article is published with open access at Springerlink.com

\begin{abstract}
Pregnancy in chronic dialysis patients is unusual and associated with many complications. Infants are often born both prematurely and small for gestational age. We report a case of a 36-year-old diabetic hemodialysis patient G4P3 who had prolonged hyperemesis gravidarum, for whom intradialytic parenteral nutrition (IDPN) was started at week 14 and continued throughout her pregnancy. She delivered a $3.5-\mathrm{kg}$ baby girl at the 36th week of gestation by cesarean section. We discuss the use of IDPN as adjunct therapy for pregnant dialysis patients.
\end{abstract}

Keywords Pregnancy ·

Intradialytic parenteral nutrition $\cdot$ Fetal outcomes

D. Tuot $\cdot$ L. A. Frassetto $(\bowtie)$

Department of Medicine, University of California, UCSF campus box 0126, rm M1202, San Francisco, CA 94143, USA

e-mail: frassett@gcrc.ucsf.edu

D. Tuot $\cdot$ S. Gibson $\cdot$ L. A. Frassetto

Division of Nephrology, University of California,

San Francisco, CA, USA

\section{A. B. Caughey}

Department of Obstetrics, Gynecology, and Reproductive Sciences, University of California, San Francisco, CA, USA

\section{Introduction}

Pregnancy is rare among childbearing women with end-stage renal disease (ESRD) on renal replacement therapy. Rate of conception in dialysis patients has ranged from $0.9 \%$ in 1980 to $2.4 \%$ in 1998 [1, 2]. While still uncommon, the incidence of pregnancy in women with ESRD seems to be increasing. However, the few successful pregnancies are often associated with a wide range of complications, including spontaneous abortion, preterm birth, intrauterine growth restriction, polyhydramnios and fetal demise [3]. Advances in dialysis technology, obstetrical monitoring, and neonatal intensive care over the last twenty years have dramatically improved fetal survival rates to roughly $80 \%$ [1], yet the mean gestational age at delivery is still 32 weeks, and preterm birth is seen in $80 \%$ of pregnancies in dialysis-dependent women [4].

Indeed, these pregnancies are challenging both for the patients and their providers. Intensive dialysis regimens are believed to reduce the fetal uremic environment, minimize large fluid shifts and placental hypoperfusion and allow greater dietary freedom with nutritional benefits [5, 6]. Trends toward improved fetal and maternal outcomes have been noted with increased dialysis delivery [7, 8], and a negative correlation between gestational age and birth weight and maternal blood urea nitrogen level has been observed [9]. Intensive hemodiafiltration has also been associated with improved fetal outcomes [3]. 
Nocturnal hemodialysis, an emerging mode of intensive dialysis with $35-56 \mathrm{~h} /$ week of therapy, has been associated with higher fertility rates among women, as well as improved fetal outcomes, compared to previous reports [10]. While there has never been a direct comparison of standard and intensive dialysis regimens in pregnant women, $20 \mathrm{~h} /$ week of dialysis seems to be the minimum recommended dose to improve fetal outcomes [1]. This requires significant commitment from the patient, dialysis center and healthcare team.

Adequate maternal nutrition is a backbone of good prenatal care. The key components of a healthy diet during pregnancy include increased protein intake of approximately $1.2 \mathrm{~g} / \mathrm{kg}$, appropriate vitamin and mineral supplementation, and consumption of a variety of foods, all leading to an appropriate weight gain of $11.5-16 \mathrm{~kg}$ per singleton pregnancy [11]. Maintaining adequate nutrition with renal failure is a well-described challenge for patients with ESRD [12, 13]. Thus, pregnant women on dialysis face additional difficulties achieving adequate nutrition. For example, pregnant women on dialysis must ingest at least $1.8 \mathrm{~g} /$ $\mathrm{kg}$ /day of protein to maintain a neutral nitrogen balance [5] and increase their caloric intake by 300 kilocalories to prevent wasting [14]. The intensive dialysis regimens of pregnancy lead to increased losses of water-soluble vitamins in the dialysate, thus requiring ample supplementation of folic acid, zinc and renal-formulated multivitamins. In addition, the calcium-phosphorus product must be monitored closely to promote adequate fetal skeletal development, while preventing complications associated with metabolic bone disease [14]. Despite awareness surrounding these increased needs, there is a paucity of literature to help practitioners develop a dietary protocol for their pregnant dialysis patients.

On this challenging backdrop, the presence of hyperemesis gravidarum makes managing such patients even more difficult. Hyperemesis gravidarum is a condition defined by unexplainable, intractable vomiting and dehydration, leading to $>5 \%$ of prepregnancy weight loss [15]. It affects $0.3-2 \%$ of pregnant women and may require nutritional support to maintain fetal and maternal health.

We describe a case of a pregnant woman with ESRD and severe hyperemesis gravidarum who was treated with intradialytic parenteral nutrition (IDPN) for the last 22 weeks of her pregnancy. Details of her nutritional status, dialysis regimen, and obstetric management are included. In the discussion, we review the role of IDPN in pregnancy, ESRD and finally in neonatal outcomes in women with ESRD.

\section{Case report}

A 36-year-old woman, gravida four, para three, with ESRD presumed secondary to diabetes in the absence of a biopsy, initiated on hemodialysis eight months prior, presented to the emergency room with one week of intermittent abdominal pain, nausea and vomiting, and was found to be 8 weeks pregnant by ultrasound dates. Her past medical history included insulindependent diabetes mellitus for 11 years associated with mild proliferative retinopathy and hypertension requiring multiple medications. Her surgical history was significant for three prior term cesarean sections. Given the increased risk of maternal mortality and fetal complications associated with pregnancy in ESRD, she underwent intensive counseling and ultimately elected to continue with the pregnancy. At that point, her dialysis regimen was intensified to a regimen consisting of $24 \mathrm{~h} /$ week (four hour treatment sessions on six days per week). Dialysate composition consisted of potassium $4 \mathrm{mmol} / \mathrm{L}$, bicarbonate $25 \mathrm{mmol} / \mathrm{L}$, calcium $1.25 \mathrm{mmol} / \mathrm{L}$ and sodium $140 \mathrm{mmol} / \mathrm{L}$. The dialysate was supplemented with an IV infusion of potassium phosphate $30 \mathrm{mmol}$ with each dialysis run, on account of persistent hypophosphatemia from poor oral intake and intensive dialysis. Dialysate flow was $800 \mathrm{ml} / \mathrm{min}$, and blood flow was $400 \mathrm{ml} / \mathrm{min}$ via a left upper extremity AV fistula. Her mid-week standardized Kt/V was 1.42 (range 1.261.59). She was anticoagulated with unfractionated heparin. Her medications consisted of labetolol $100 \mathrm{mg}$ twice per day, prenatal multivitamin one tablet daily, folic acid $1 \mathrm{mg}$ daily, vitamin B6 $100 \mathrm{mg}$ daily, calcium carbonate $1,250 \mathrm{mg}$ with meals, erythropoietin IV three times a week (TIW) to keep hemoglobin levels between 10 and $11 \mathrm{~g} / \mathrm{L}$, IV iron supplementation according the dialysis unit anemia management protocol (total 1,200 mg in nine months) and oral calcitriol $0.25 \mathrm{mg}$ TIW.

Weeks after her pregnancy was discovered, she continued to have abdominal pain and vomiting requiring hospitalization; further workup of elevated serum liver enzyme levels including an abnormal 
abdominal ultrasound revealed cholelithiasis with acute cholecystitis. Due to heightened surgical risks associated with pregnant patients, initial management of the acute disease was conservative, with bowel rest and IV hydration. She continued suffering from recurrent attacks of abdominal pain and vomiting, with continual inability to maintain appropriate caloric intake, and persistently elevated serum liver enzyme levels. At 14 weeks of pregnancy, her estimated dry weight (EDW) was $71.5 \mathrm{~kg}$, a $5.5 \mathrm{~kg}$ loss compared to her pre-pregnancy dry weight of $76 \mathrm{~kg}(155 \% \mathrm{IBW}$, $\left.\mathrm{BMI}=31.1 \mathrm{~kg} / \mathrm{m}^{2}\right)$ and her nutritional protein catabolic rate (nPCR) was only 0.55 . Intradialytic parenteral nutrition (IDPN) was thus initiated. Her estimated nutrient requirements were 2,100-2,250 kilocalories (kcal) $\left[{ }^{1} \mathrm{REE} \times 1.2-1.3+300 \mathrm{kcal}\right.$ for pregnancy] and $75-85 \mathrm{~g}$ protein $\left[{ }^{2} \mathrm{MAW} \times 1.4-1.5\right]$. The IDPN provided $95 \mathrm{~g}$ of protein $(15 \%$ amino acids, $380 \mathrm{kcal}), 100 \mathrm{~g}$ dextrose $(340 \mathrm{kcal})$ and $40 \mathrm{~g}$ of lipid (400 kcal) for a total of 1.5 calories $/ \mathrm{ml}$ and $1,120 \mathrm{kcal}$ per bag. She received one bag of IDPN at each dialysis session. At 18 weeks of pregnancy, she underwent laparoscopic cholecystectomy without complications for persistently symptomatic cholecystitis.

After surgery, her liver enzymes normalized, yet she continued to experience intractable nausea and vomiting for two subsequent months without a clear etiology. While she was unable to reliably complete calorie count questionnaires, she would always remark on her inability to consume a normal meal and her serum phosphorous levels declined even further than expected for her intensive dialysis regimen. Furthermore, her weekly ultrafiltration requirements remained extremely low, averaging $1.1 \mathrm{~L}$ per week, further confirming her very poor PO intake. She was thus diagnosed with severe hyperemesis gravidarum and was unsuccessfully treated with anti-emetics. She continued to have poor appetite and weight loss until week 26 of her pregnancy, when her EDW stabilized between 72 and $74 \mathrm{~kg}$, rather than continuing its downward trajectory.

For the remainder of her pregnancy, she was maintained on IDPN, the frequency of emeses decreased, and she started to eat more regularly. Her EDW slowly increased, demonstrating true weight

\footnotetext{
${ }_{1}$ REE-Resting energy expenditure.

2 MAW-metabolically active weight.
}

gain, as she never developed any edema or other signs of increased extracellular volume. While her albumin never improved, her pre-albumin did increase with time, up to $33 \mathrm{mg} / \mathrm{dL}$ at week 29. In addition, her nPCR rose, from a nadir of 0.55 at week 12 of pregnancy prior to starting IDPN, to a height of 1.65 at week 20 . For comparison, her pre-pregnancy nPCR was 1.23.

Fetal monitoring occurred with frequent, serial ultrasounds. Despite poor maternal nutrition, obstetric ultrasounds at 17, 29 and 33 weeks of gestation revealed normal fetal weight for gestational age. Polyhydramnios was noted on ultrasound at week 33, and given the ongoing risk of maternal and fetal complications, including fetal demise; she was admitted to the hospital for a cesarean delivery at 36 weeks of gestation after undergoing an amniocentesis for fetal lung maturity. The female neonate weighed 3,505 g, with Apgar scores of 7 and 9.

\section{Discussion}

Although parenteral nutrition has been used in pregnant women with normal renal function and in non-pregnant patients with renal failure, its use in pregnant dialysis-dependent patients has been reported only once [16]. The lack of literature in part reflects the uncertainty and controversy associated with the use of parenteral hyperalimentation.

In a recent prospective, randomized study of 200 malnourished hemodialysis patients, no significant advantages of IDPN in addition to a successful oral supplementation program were demonstrated, in terms of mortality or morbidity. Both the control and IDPN groups, however, exhibited improvement in nutritional status, as defined by serum albumin, serum prealbumin and BMI [17]. This is important to note, as increases in serum pre-albumin levels during nutritional therapy was associated with decreased mortality and hospitalization risk. This corroborated the results of previous randomized studies that showed improvement in body weight and nutritional parameters in hemodialysis patients receiving some form of supplemental nutrition, including IDPN alone [18]. IDPN has also been noted effective in ESRD patients with acute medical or surgical illnesses causing states of hypercatabolism, such as sepsis, pancreatitis and inflammatory states that develop after lower limb amputation [19]. 
Pregnancy, regardless of renal function, is also a state of increased metabolic demand. Pregnant women who suffer from severe hyperemesis gravidarum cannot match their caloric and protein intake with their increased needs; total parenteral nutrition (TPN) has been used safely in such settings to ensure adequate maternal nutrition and normal fetal growth $[15,20]$. However, TPN is associated with infectious complications as well as those associated with central catheter placement. Better pregnancy outcomes with fewer infectious complications (UTI, pneumonia) occur in women who need short-term TPN rather than those women who require long-term hyperalimentation $[20,21]$. Therefore, great care should be taken to select appropriate pregnant patients for use of parenteral nutrition.

The case presented here describes a pregnant woman with severely compromised oral intake and weight loss due to cholecystitis and persistent hyperemesis gravidarum, superimposed on a malnourished state associated with ESRD. Despite her complicated clinical course, after initiation of IDPN, her weight stabilized. Over time, the parenteral nutrition helped improve her metabolic and nutritional parameters and enabled her to regain most of the weight that she had lost between weeks 9 and 14 of her pregnancy. Her pre-albumin levels increased from 29 to 33, and her weight at delivery was $85 \mathrm{~kg}$, representing a $9 \mathrm{~kg}$ weight gain from her non-pregnant weight.

Preterm infants born to dialysis patients are often small for gestational age, as well as premature [4, 22]. Our patient carried her pregnancy to near term and delivered a healthy female neonate, who was normal in size and weight throughout the pregnancy, despite the months of poor oral intake and weight loss.

While pregnant women with diabetes are known to have large infants [23], the patient in this case had normal blood sugars throughout her pregnancy and $\mathrm{HgA} 1 \mathrm{C}$ levels that fluctuated between 4.3 and $5.1 \%$ without medication. The baby's normal birth weight was thus less likely a product of maternal glucose intolerance and more likely a reflection of adequate maternal nutrition, largely achieved with IDPN. Iron deficiency has also been associated with reduced fetal growth [24]; this patient's iron studies were always within the normal range and monitored every three months.

Though controversial, improvements in dialysis, obstetrical care and antenatal fetal monitoring over the past two decades appear to have increased fertility rates and successful pregnancies in dialysis-dependent women. Moving forward, more robust studies are needed to further improve maternal and fetal health and to develop guidelines for practitioners caring for this complex patient population. This case highlights the importance of nutritional supplementation in pregnant patients with ESRD and suggests that IDPN may be associated with improvement or normalization of fetal birth weights.

Open Access This article is distributed under the terms of the Creative Commons Attribution Noncommercial License which permits any noncommercial use, distribution, and reproduction in any medium, provided the original author(s) and source are credited.

\section{References}

1. Okundaye I, Abrinko P, Hou S (1998) Registry of pregnancy in dialysis patients. Am J Kidney Dis 31(5):766-773

2. Rizzoni G, Ehrich JH, Broyer M, Brunner FP, Brynger H, Fassbinder W, Geerlings W, Selwood NH, Tufveson G, Wing AJ (1992) Successful pregnancies in women on renal replacement therapy: report from the EDTA registry. Nephrol Dial Transplant 7(4):279-287

3. Haase M, Morgera S, Bamberg C, Halle H, Martini S, Hocher B, Diekmann F, Dragun D, Peters H, Neumayer HH, Budde K (2005) A systematic approach to managing pregnant dialysis patients-the importance of an intensified haemodiafiltration protocol. Nephrol Dial Transplant 20(11):2537-2542

4. Chou CY, Ting IW, Lin TH, Lee CN (2008) Pregnancy in patients on chronic dialysis: a single center experience and combined analysis of reported results. Eur $\mathrm{J}$ Obstet Gynecol Reprod Biol 136(2):165-170

5. Giatras I, Levy DP, Malone FD, Carlson JA, Jungers P (1998) Pregnancy during dialysis: case report and management guidelines. Nephrol Dial Transplant 13(12):32663272

6. Smith WT, Darbari S, Kwan M, O'Reilly-Green C, Devita MV (2005) Pregnancy in peritoneal dialysis: a case report and review of adequacy and outcomes. Int Urol Nephrol 37(1):145-151

7. Prasad S, Parkhurst D, Morton MR, Henning P, Lawton J, Bannister K (2003) Increased delivery of haemodialysis assists successful pregnancy outcome in end-stage renal failure. Nephrology (Carlton) 8(6):311-314

8. Eroglu D, Lembet A, Ozdemir FN, Ergin T, Kazanci F, Kuşcu E, Haberal M (2004) Pregnancy during hemodialysis: perinatal outcome in our cases. Transplant Proc 36(1):53-55

9. Asamiya Y, Otsubo S, Matsuda Y, Kimata N, Kikuchi K, Miwa N, Uchida K, Mineshima M, Mitani M, Ohta H, Nitta K, Akiba T (2009) The importance of low blood urea nitrogen levels in pregnant patients undergoing 
hemodialysis to optimize birth weight and gestational age. Kidney Int 75(11):1217-1222

10. Barua M, Hladunewich M, Keunen J, Pierratos A, McFarlane P, Sood M, Chan CT (2008) Successful pregnancies on nocturnal home hemodialysis. Clin J Am Soc Nephrol 3(2):392-396

11. Kaiser L, Allen LH (2008) Position of the American dietetic association: nutrition and lifestyle for a healthy pregnancy outcome. J Am Diet Assoc 108(3):553-561

12. Ikizler TA, Hakim RM (1996) Nutrition in end-stage renal disease. Kidney Int 50(2):343-357

13. Mafra D, Farage NE, Azevedo DL, Viana GG, Mattos JP, Velarde LG, Fouque D (2007) Impact of serum albumin and body-mass index on survival in hemodialysis patients. Int Urol Nephrol 39(2):619-624

14. Molaison EF, Baker K, Bordelon MA, Brodie P, Powell K (2003) Successful management of pregnancy in a patient receiving hemodialysis. J Ren Nutr 13(3):229-232

15. Ghani R (2003) The use of total parenteral nutrition in protracted hyperemesis gravidarum. J Obstet Gynaecol 23(2):199-201

16. Brookhyser J (1989) The use of parenteral nutrition supplementation in pregnancy complicated by end-stage renal disease. J Am Diet Assoc 89(1):93-94

17. Cano NJ, Fouque D, Roth H, Aparicio M, Azar R, Canaud B, Chauveau P, Combe C, Laville M, Leverve XM, French Study Group for Nutrition in Dialysis (2007) Intradialytic parenteral nutrition does not improve survival in malnourished hemodialysis patients: a 2-year multicenter, prospective, randomized study. J Am Soc Nephrol 18(9): 2583-2591
18. Navarro JF, Mora C, León C, Martín-Del Río R, Macía ML, Gallego E, Chahin J, Méndez ML, Rivero A, García J (2000) Amino acid losses during hemodialysis with polyacrylonitrile membranes: effect of intradialytic amino acid supplementation on plasma amino acid concentrations and nutritional variables in nondiabetic patients. Am J Clin Nutr 71(3):765-773

19. Korzets A, Azoulay O, Ori Y, Zevin D, Boaz M, Herman M, Chagnac A, Gafter U (2008) The use of intradialytic parenteral nutrition in acutely ill haemodialysed patients. J Ren Care 34(1):14-18

20. Lee RV, Rodgers BD, Young C, Eddy E, Cardinal J (1986) Total parenteral nutrition during pregnancy. Obstet Gynecol 68(4):563-571

21. Folk JJ, Leslie-Brown HF, Nosovitch JT, Silverman RK, Aubry RH (2004) Hyperemesis gravidarum: outcomes and complications with and without total parenteral nutrition. J Reprod Med 49(7):497-502

22. Bamberg C, Diekmann F, Haase M, Budde K, Hocher B, Halle H, Hartung J (2007) Pregnancy in intensified hemodialysis: fetal surveillance and perinatal outcome. Fetal Diag Ther 22:289-293

23. Sacks DA (2007) Etiology, detection, and management of fetal macrosomia in pregnancies complicated by diabetes mellitus. Clin Obstet Gynecol 50(4):980-989

24. Christian P, West KP, Khatry SK, Leclerq SC, Pradhan EK, Katz J, Shrestha SR, Sommer A (2003) Effects of maternal micronutrient supplementation on fetal loss and infant mortality: a cluster-randomized trial in Nepal. Am J Clin Nutr 78(6):1194-1202 